\title{
A NEUROETHOLICAL STUDY OF HUMAN BEHAVIOR IN THE CONTEXT OF MEDITATION IN RELIGIONS
}

\begin{abstract}
A neuroethological examination of the behavior and the cognition of nonhuman and human beings shows a connection between biological specializations to social behavior. It shows that ancestral organs and manners are usually regulated differently, duplicated, and repurposed so that an animal can act in a particular way. A neuroethological approach shows that highly specialized mechanisms have changed over time to translate immediate parallel circuits and social contexts that have changed over time. According to this approach, highly specialized mechanisms have changed to enable translation of perceived nonsocial and social signals into partially interconnected nonsocial and shared motivational pointers that have together created general-purpose techniques that command behavior. Dissimilarities in social conduct between species and between members of a species are partly due to neuromodulatory regulation of neutral circuits that appears to be controlled partly by genetics. The intraspecific difference in social behavior is important as it assists an animal to adapt to a particular situation. This review suggests that neuroethological approach to human behavior can assist in the understanding of human behavior.
\end{abstract}

Keywords: Neuroethological, human behavior, meditation, religions.

\section{Human Behavior and Analysis of Consciousness}

Responsiveness and sensitivity to information about other people are important for survival [1, pp. 960-967]. They can lead to human health, financial success, and other benefits. People navigate the social world through tracking the behaviors of other people and forming a model of their emotions and intentions. They actively search for and share information about other people in order to alter their own behaviors in light of the behaviors of other people. The specializations for social actions show rich evolutionary history to adjustment to life in a group. Just like a number of nonhuman primates, human beings live in groups characterized by patterned social conducts such as cooperative foraging, imitation, grooming, mating, competitive interactions, and ritualized courtship. Therefore, corruption of social environment affects individual animal or human as well as their reproductive success.

A complete theory of consciousness does not exist [2, p. 11]. Both materialism and dualism are wrong because they deny the existence of consciousness in the physical world. Therefore, computationalism, behaviorism, readiness potential, materialism, subjectivity, and epiphenomenalism hold false claims. Epistemic objectivity is not precluded by ontological subjectivity [3]. Consciousness creates observer-relative phenomena but consciousness itself is not observer-relative. It consists of sentience, feeling, or awareness of ontological subjectivity, qualitativeness, intentional causation, intentionality, and unified conscious field. Neurobiological processes in the lower side of the brain determine all conscious states recognized as higher-level features in the brain.

Consciousness consists of all states of awareness, sentience, or feeling. It starts from the time an individual wakes up from a dreamless sleep to the time he/she sleeps again, dies, or becomes unconscious. Consciousness has many features. Five most important features are qualitativeness, ontological subjectivity, unity, intentionality, and intentional causation [2, p. 24]. Intentional causation and intentionality enable people to cope with the environment.

\section{The Failure of Sociobiology}

Apart from the need for survival, Darwinian revolution added a diachronic element to the Aristotelian teleological cause. The diachronic element is appropriate for a particular period only. Darwinian thought, however, cannot be used to explain everything. In the past, sociologists used sociobiology to explain human morality, civilization, culture, philosophy, and others.

\footnotetext{
* Hubert Jurjewicz

College of Saint Elizabeth, Morristown, USA

E-mail: hjurjewicz@gmail.com
} 
E.O. Wilson (1975) developed the theory based on Darwinism. However, even though it is a theory based on Darwinism, sociobiology failed to do what it was created for.

Sociobiology failed because, it tried to clarify specific elements of human society and culture. An explanation through sociobiology had to take into account the fact that a key change in human gene pool has not happened in the past 30,000 years. It had to consider the fact that there have been enormous changes in the human society in the last 30,000 years. There has been a rise of things like communism, fascism, democracy, and enlightenment. There is thus no relationship between the social reality and the social evolution. Even when the number of years is reduced to the past 3000 years, sociobiology still lacks validity. It cannot explain why there have been major changes yet there have been no key changes in the gene pool of human beings.

Wilson concentrated on cultural universals to strengthen sociobiology. He concentrated on incest taboo as all societies have incest taboos. Even though sociobiology explained the existence of taboo, cultural anthropologists refuted the explanation claiming that cultures do not have similar incest taboos. In some cultures, it is wrong to marry your cousin while it is allowed in others. However, all societies forbid father-daughter, brother-sister, and mother-son sexual relations. Despite this fact, sociobiology cannot be said to have succeeded because it inadequately explained universal prohibition. Humans have no internal inhibition for a sexual act with people they are related with. If they had, there would be no need for a taboo.

The lack of sexual desire between people who are closely related is due to aversion. Studies have shown that children in one Israeli kibbutz have a tendency to have no sexual desires for other persons in the same kibbutz. They, however, tend to develop strong sexual desires for persons raised in other kibbutz as close proximity causes sexual aversion during development. Sexual aversion gives incest taboo, causal or mechanical explanation. The importance of biparental reproduction gives the incest its functional explanation. However, the functional explanation does not offer specific intentional content to the prohibition. Furthermore, the power of prohibition is not given as the tendency to act in a particular manner lacks.

\section{Evolution and Social Behavior}

Social conduct places unique and strong strain on the nervous system. Social complexity of a species correlates with the forebrain volume. This is after correction with body size has been made. Social complexity of neural mechanisms is related to diets high in dependable calories-rich foods. Key growth of hominines' brains during the evolution concurs with the creation of novel conducts that increased calories in diets [4, p. 42].

Social behavior tends to depend on homologous neural mechanisms. New conducts can be created through elaboration or repurposing ancestral mechanisms, which served a different purpose in the past. For example, electrosensory receptors, which are part of the lateral line systems of mormyrid fishes, develop to support detection of motion and orienting [5, p. 329]. Cerebellum, which processes feelings from lateral line system is enlarged in mormyrid fishes but is absent in their ancestors because they lacked a social function served by the cerebellum. Evolution of neuropeptide oxytocin (OT) is another example of repurposing a feature for a social function. Tolerance and approach enhancing roles of OT ancestors of vertebrates evolved to support social bonding and parental behavior in mammals [6, p. 2259-2271].

General-purpose mechanisms support sociality in some cases while in other cases it might require special-purpose mechanisms. General-purpose organs are utilized across both social and nonsocial domains while special purpose organs serve only a particular role in the social domain. Specialized organs like electrosensory receptors in mormyrid fishes are usually found in the input stages of social processing but general mechanism is more in the input stages of social processing, but generalized organs are high in number near output stages of effective control. In contrast, a mixture of generalized and specialized organs characterize transitional computational phases of processing, which interpret socially definite inputs into motivational indications, which guide decision making and learning to generate behavior [7, p. 2270].

\section{Nonsocial and Social Behaviors}

Reinforcement drives a large number of human conducts. Human and nonhuman primates forage to acquire various rewards. All motile and heterotrophic life forage as foraging is the most basic and primitive behavior. Foraging approaches are under strong pressure to be changed or modified for maximization of returns in investments. Usually, animals look for foods that are distributed sparsely. Food materials are depleted as animals continue foraging. When a number of food materials go down, the consumption rate of energy slows down. At this point, animals can decide to move to a new patch. However, due to circumstances like the costliness of doing so and the uncertainties accompanying the act, animals, which include people may decide to abandon the decision to move into another patch. The same principle is applicable to many other situations facing people as resources are sparsely distributed. According to Charnov's Marginal Value Theorem, abandonment of a patch should be done when there is a fall in the rate of consumption.

Organisms can forage information. Like other forms of foraging, information foraging has costs and opportunities. Costs like missed opportunities to sleep, drink, and eat, as information- seeking behaviors usually require someone to act in a particular manner. Social information has either negative or positive reinforcement value. Therefore, the foraging theory 
can be utilized to study the acquisition of social information. According to several studies, both nonhuman, and human primates constantly seek social information. They find social stimuli to be intrinsically rewarding. Other social stimuli are more reinforcing and interesting than others. For example, human infants stare for long at faces as compared to the time they take to gaze at nonfaces similar to the real faces. Nonhuman primates have been found to gaze for long towards higher-ranking animals as compared to lower ranking animals. Therefore, brain of most animals have developed mechanism to acquire and utilize social information, these show that social information is important and that it is worth to forage.

Another similarity between nonsocial and social behaviors can be found through assessment of behavioral reactions to social and predators' threats. In both cases, a looming threat causes reflexive behaviors like defensive aggression, freezing, and escape behavior. A distant threat causes the vigilant exploratory conduct in the object that is threatened. For example, a rhesus macaque will choose to gaze at a picture of a dominant monkey other than of the picture of the subordinate, when given a chance. In spite of this fact, low-status monkeys usually avert their gaze on the faces of high-status monkeys when confronted. This kind of behavior is a reminder of exploratory when there is a distant threat and avoidance behavior when there is a real threat. Many basic behavioral strategies that are created from nonsocial settings are also applicable in social settings.

\section{Reflective and Reflexive Empathy in Humans and Animals}

Reflective and reflexive mental state is linked to and plays an important part in the promotion of social bonds. Individual difference in the enthusiasm to attend to social challenges and social interactions is positively correlated with measures that are associated with the formation of social bonds. What an individual thinks or knows is usually confounded because reflective processes related with higher levels of ToM and linked closely to reflexive, automatic processes [8, p. 6:224]. Even though, humans are conscious of the differences between their own and other's mental states, they are usually unaware of the basis of their awareness or feelings. For example, both goal-directed behavior and response to a gaze activate a more primitive side of the brain as well as higher cortical sides like prefrontal cortex. This is true of intended behavior.

Even though people can consciously access their reflections on whether their actions are intentional or accidental, many neuronal reactions, which contribute to the ultimate decision, are usually subconscious. In both monkeys and humans, mirror neurons that are in the lower parietal lobule become activated when a person acts in a particular way or when he/she observes another person performing them. Many neurons start to be active before the other person performs the action in reality. This suggests that neurons encode acts as well as actor's intentions [9, p. 28]. Our ability to identify gaze as informative element or to consider whether a conduct is intended or not depends on automatic and reflexive neuronal activity that people are largely ignorant about.

Empathy also has similar impacts. Explicit and reflective empathy consist of the capability to identify emotional states such as fear or grief in others without the necessarily going through the same emotion. Reflective empathy causes activity of neurons in higher part of the brain like the cortex and in the primitive parts of the brain like the brainstem, endocrine, midbrain systems, which are associated with social attachment, reactivity, and reward [10, p. 37]. Even though individuals can distinguish between their own emotions from those of others, representation of emotions likes disgust, shame, and pain cause activation of the same areas of the brain they are experienced. Being nice to and feeling sympathy for other people is emotionally rewarding as it causes the release of dopamine, a neurotransmitter associated with individual reward. Neuropeptides are also activated to release oxytocin associated with maternal attachment, empathy, trust, and sensitivity towards others' affective states [11, p. 331-336].

Similar to this, is reflective imitation. Reflective imitation involves the ability of an animal or a human being to recognize the intentions and the goals of others and the view that in order to acquire the same goal one ought to copy the actions of another individual. Just like great apes, human depend greatly on this ability [12, p. 31-38]. A large number of people are not aware that they continuously mimic others. People have an unconscious and reflexive tendency to copy traits, mannerisms, and postures of people they are in interaction [13].

\section{A Physiology of Fear}

A frightened individual experiences various physiological changes. One of these common changes is the standing up of hair. Other changes include the stimulation of sympathetic nervous system in cases of freeze, fight, or flight. A neurologist by the name Melvin Konner noted that nerve net, which is balanced by the braking power of the parasympathetic systems, starts an increase in heart rate, blood pressure, and flow of blood to the muscles. It also reduces the flow of blood to the viscera. The changing balance further sparks reflexive emptying of bowels and bladder to prepare an animal for a flight or fight. However, this may humiliate an individual who is found at the verge of a fight he/she cannot handle [14, p. 14].

In addition, fear instigates release of hormones like adrenaline, cortisol, and Corticotropin-releasing hormone (CRH). Neurologists have been able to manipulate these hormones in the laboratory to create a more or less fearful behavior in mammals. Scientists have noticed that insertion of a gene, which makes 
$\mathrm{CRH}$ on a mouse, produces a very fearful mouse while removal of the gene from the mice led to an extremely fearless mouse [ 15 , p. $3567-3577]$.

All mammals have adaptive instincts like flights or fight but are old-brain systems situated in brain stems. On top of this midbrain, systems are limbic emotional circuits. Emotional neuroscience has identified seven key emotional systems, which mammals fear. These are care, fear, rage, lust, play, seeking, and panic. Each has distinctive pathways via the brain, specific hormones, and specific neurotransmitters. These characteristics cause specific mammal behaviors. For example, fear has a neurocircuitry, which goes from amygdala via the hypothalamus to periaqueductal gray (PAG), to the brain stem, and then out via the spinal cord. Fear in human and other mammals is regulated largely in the amygdala. Joseph E. LeDoux mapped the pathway by which memory and fear work in the cycle to develop conditioned learning [16, p. 27]. Therefore, when an individual relates a dog with aggression, his/ her brain will cycle through the same circuit to cause behavior. Fear is situated in the same place in mammals.

\section{Darwinian Roots of Horror}

Just like other biological traits, fear is subjected to evolution. Mammals have heritable dispositional levels of timidity and fear. The levels of shyness can be promoted through breeding to create populations that are more fearful. For example, rats that were fearful were bred. In only ten generations of breeding, scientists had 10 times more fear in the population. The results of this study confirmed that earlier discoveries by Darwin himself discovered that chimps feared snakes. He repeatedly took fake and real snake to a zoo in London to study the reaction of the chimps to the fake and the real snake. He explained the existence of fear among the chimps by pointing to the rudimentary taxonomic recognition system, which is wired into animals.

\section{Meditation}

Meditation is a contemplative practice that exists in almost all key religions [17]. Meditation cultivates basic human qualities like compassion, love, mindfulness, sense of caring, a clear mind, and emotional balance. These are qualities, which remain latent if the effort is not put to develop them. Meditation also assists people to familiarize with a more serene and flexible situation. It is an uncomplicated activity; it does not require workout attire or equipment. A meditator starts meditation by taking a relaxed physical posture. $\mathrm{He} / \mathrm{she}$ is neither too relaxed nor too tense. A meditator expects that the meditation will cause selftransformation and achievement of the wishes and the desires of other people. After meditation, the practitioner ought to stabilize his/her mind because it is disorderly. The mind is full a flow of inner chatter after meditation. Mastering the brain involves liberating it from inner confusion and automatic way of being.

\section{a) Focused-Attention Meditation}

While at Emory University, Wendy Hasen-camp and her team members utilized brain imaging to spot neural networks that become active due to focused-attention meditation. In the study, participants were requested to concentrate their focus on the sensation they create by breathing [18]. During meditation, participants' minds wandered away from the focus. However, they realized this and restored their focus on the rhythm of exhaling and inhaling. The practitioners were required to press a button to signal the wandering of the mind. Researchers recognized four stages of a cognitive cycle in this particular study on focusedattention meditation. They are the wandering of the mind, the time of getting aware of the distraction, period of redirecting the direction, and beginning focused awareness.

Each phase among the four stages consists of certain brain networks. Default-mode network (DMN) is motivated in the first part of the cycle when there is a distraction. DMN consists of areas of the posterior cingulated cortex, inferior parietal lobe, medial prefrontal cortex, lateral temporal cortex, and precuneus. DMN is activated when the mind wanders. It plays a general part in updating and building inner models of the world based on long time memories about others and oneself. Salience network regulates subjectively perceived feelings that can distract an individual. It plays an important role in the detection of new events and switching of activities during mediation. For instance, it may alter concentration away from the default-mode network. In the second phase, a meditator becomes aware of the distraction. The areas of the brain that are involved are the anterior cingulated cortex, anterior insula, regions known as salience network.

The third phase involves areas like lateral inferior dorsolateral prefrontal cortex. The organ ensures that an individual develops back attention by causing detachment between the areas and distracting stimulus. The last, fourth stage consists of dorsolateral prefrontal cortex, which maintains a high level of activity as the practitioner focuses on an object like school.

In another study at Wisconsin, researchers realized that practitioner's level of experience influenced the rate and the pattern of activity in the brain. Well-experienced meditators show more activity in attention-relate parts of the brain when contrasted with inexperienced meditators. Advanced meditators seemed to have developed skills that enabled them to acquire a focused state of mind without much difficulty.

\section{b) Open-Monitoring Meditation}

Mindfulness necessitates a meditator to concentrate every sound or sight and track inner self-talk and internal bodily sensations [19]. The meditation makes a person become aware of everything surrounding him/her but encourages him/her to avoid thoughts or perceptions returning when the mind wanders 
away. Consciousness of what is happening in the surrounding develops with time. It helps an individual who has gone through a meditation to develop a sense of psychological well-being. Usual irritants in the surrounding lose their disruptiveness. They become less disturbing.

In a study to measure mindfulness attention at Wisconsin, participant were required to perceive two numbers that were presented rapidly on the screen, when a second number appeared after about 300 milliseconds after the first, the participants did not detect them. They could easily identify the second number if the number appeared after the first number had stayed for 600 milliseconds. The attentional blink, which is a phenomenon that exists when an individual is unable to detect a second object showed that the brain lacks the capability to process two stimuli that are presented to an observer at close interludes. However, mindfulness training can assist people to notice more than one stimulus. Mindfulness practice helps an individual to cultivate nonreactive forms of sensory awareness that cause a reduction in attention blink.

Being conscious of a disagreeable sensation can lower maladaptive emotional reactions. In a more advanced mindfulness meditation known as open presence, the mind is relaxed, calm, and not focus on anything but is completely free of dullness and excitation. The meditator is open to experience without the need for interpretation, rejection, change, or ignorance of a painful sensation. The intensity of the pain does not reduce after a meditation. However, meditation assists an individual in developing the ability to manage and buffer physiological reactions like the release of stress hormone or inflammation. Expert meditators' brains are different from those of other people. There is a reduced activity in anxiety-related regions of expert meditators' brain. Anxiety-related regions include the amygdala and insular cortex. A meditator's brain becomes more accustomed to stimulus more quickly than novice does.

c) Compassion Meditation

The third form of meditation is the one, which cultivates feelings and attitudes of compassion and loving kindness towards people. It cultivates love and compassion even to strangers, enemies, or people who are not close relatives. It assists a meditator to develop an awareness of the needs of other people and then experience a compassionate and a sincere desire to assists. In order for this to happen, a meditator ought to have the feelings of the other people. However, even if an individual has developed feelings that are similar to those of a suffering person, the individual is not expected to develop the compassionate mindset straight away. Unselfish desire drives this type of meditation. It thus leads people to want to assist people who are suffering.

A meditator starts by first focusing on unconditional feeling of love and benevolence for other individuals. Studies have shown that insular cortices and secondary somatosensory, which usually take part in empathetic and any other emotional response is activated more among experts as compared to among novice. This tendency showed that experts have an ability to understand and share the feelings of other people without becoming overwhelmed by emotions. Furthermore, compassion meditation causes more activity in areas like medial prefrontal cortex, temporoparietal junction, and superior temporal sulcus.

\section{Conclusion}

Neuroethological approach to human behavior proves to be useful also in contemporary attempts to understand the nature of meditation. A measurable changes in the brain and nervous system has been observed in subjects as they entered and persisted in meditative mode. Researchers recognized four stages of a cognitive cycle in a study of focused-attention meditation. They proved that mindfulness practice in an open-monitoring meditation model can help an individual to cultivate nonreactive forms of sensory awareness that cause a reduction in attention blink. They have also pointed particular areas of cerebral activity among subjects practicing compassion meditation model.

\section{References}

[1] BAREFOOT, J. C., GRONBAEK, M., JENSEN, G., SCHNOHR P., PRESCOTT, E.: Social Network Diversity and Risks of Ischemic Heart Disease and Total Mortality: Findings from the Copenhagen City Heart Study. American J. of Epidemiology, vol. 161, No. 10, 960-967, 2005. ISSN 0002-9262.

[2] SEYFARTH, R., CHENEY, D.: In the Light of Evolution: Volume VII: The Human Mental Machinery. Washington, D.C. : National Academy of Science, 2014. ISBN 978-0-309-29640-3. 
[3] As Valco and Valcova correctly point out, if "the subject and subjectivity become indifferent, the truth also becomes indifferent," therefore, "truth should rather be understood as an objective uncertainty appropriated passionately by the inward reflective experience of love and faith of the self." VALCO, M. \& VALCOVA, K.: The Epistemological Challenge of Kierkegaard's Truth is Subjectivity Principle. Communications - Scientific Letters of the University of Zilina, vol. 16, No. 3, 2014, 25. ISSN 1335-4205. Subjectivity is intimately related to authenticity and existential focus, for an authentic human being is "always oriented towards the singular and unrepeatable aim.” KONDRLA, P. \& KRALIK, R.: Authentic being and moral conscience. European J. of Science and Theology, vol. 12, No. 4, 2016, 158. ISSN 1841-0464. On these topics also see: VALCO, M., KRALIK, R. \& BARRETT, L.: Moral implications of Augustine's philosophical and spiritual journey in his Confessions. Communications - Scientific Letters of the University of Zilina, vol. 17, No. 2, 2015, 103-108. ISSN 1335-4205; KONDRLA, P. \& PAVLIKOVA, M.: From formal ethics to existential ethics. European J. of Science and Theology, vol. 12, No. 3, 2016, 101-111. ISSN 1841-0464; VALCOVA, K., PAVLIKOVA, M. \& ROUBALOVA, M.: Religious Existentialism as a Countermeasure to Moralistic Therapeutic Deism. Communications Scientific Letters of the University of Zilina, vol. 18, No. 3, 2016, 98-104. ISSN 1335-4205; PAVLIKOVA, M.: Despair and alienation of modern man in society. European J. of Science and Theology, vol. 11, No. 3, 2015, 191-200. ISSN 1841-0464; KRALIK, R. \& TOROK, L.: The moment Kierkegaard's attack upon Christendom. European J. of Science and Theology, vol. 12, No. 3, 2016, 45-53. ISSN 1841-0464.

[4] WRANGHAM, R.: Catching Fire: How Cooking Made Us Human. Philadelphia: Basic Books, 2009. ISBN 978-0-465-02041-6.

[5] KATZ, P. S.: Comparative Neurophysiology: An Electric Convergence in Fish. Current Biology, vol.16, No. 9, 2006, R327-R330. ISSN 0960-9822.

[6] YOSHIDA, M. et al.: Evidence that Oxytocin Exerts Anxiolytic Effects via Oxytocin Receptor Expressed in Serotonergic Neurons. In Mice. J. of Neuroscience, vol. 29, No. 7, 2009, 2259-2271. ISSN 0270-6474.

[7] WATSON, K. K., PLATT, M. L.: Social Signals in Primate Orbitofrontal Cortex. Current Biology, vol. 22, No. 23, 2012, $2268-2273$. ISSN 0960-9822.

[8] HECHT, E.E., PATTERSON, R. B., BARBEY, A. K.: What can other Animals Tell us about Human Social Cognition? An Evolutionary Perspective on Reflective and Reflexive Processing. Frontiers in Human Neuroscience [online], vol. 6, 2012. Available on the Internet: http://dx.doi.org/10.3389/fnhum.2012.00224

[9] RIZZOLATTI, G., FABBRI-DESTRO, M.: The Mirror Neuron System. Handbook of Neuroscience for the Behavioral Sciences. New York: Wiley, 2009. ISBN 978-0-470-08355-0.

[10] DECETY, J.: The Neuroevolution of Empathy. Annals of the New York Academy of Sciences, vol. 1231, No. 1, 2011, 35-45. ISBN 978-1174957048

[11] CARTER, C. S., GRIPPO, A. J., POURNAJAFI-NAZARLOO, H., RUSCIO, M. G., PORGES, S. W.: Oxytocin, Vasopressin and Sociality. Progress in Brain Research, vol. 170, 2008, 331-336. ISBN 978-0-12-804216-8.

[12] BUTTElmanN, D., CARPENTER, M., CAll, J., TOMASEllO, M.: Enculturated Chimpanzees Imitate Rationally. Developmental Science, vol. 10, No. 4, 2007, F31-F38. ISSN 1467-7687.

[13] For a good analysis of the potential of human communities to shape common traits or "shared values" among humans, see: JUROVA, J.: European J. of Science and Theology, vol. 12, No. 3, 2016, 101-111. ISSN 1841-0464.

[14] KONNER, M.: The Tangled Wing. New York: Times Books, 2002. ISBN 0-7167-4602-6.

[15] BRUCHEY A. K., LIMA, G.: Brain Activity Associated with Fear Renewal. European J. of Neuroscience, vol. 24, No. 12, 2006, 3567-3577. ISSN 1460-9568.

[16] LEDOUX, J. E.: The Emotional Brain. New York: Simon and Schuster. 2002. ISBN 978-0670030286; The Synaptic Self. New York: Viking, 1996. ISBN 0670030287.

[17] SLIVKA, D.: Hebraic Scriptural Hermeneutics in the Ancient Hellenistic World as the Basic Approach of Early Christians. European J. of Science and Theology, vol. 11, No. 5, 2015, 87-96. ISSN 1841-0464.

[18] RICARD, M., LUTZ, A., DAVIDSON, R. J.: Mind of the Meditator. Scientific American, vol. 311, No. 5, 2014, 38-45. ISSN 00368733.

[19] CHANG, S., BRENT, L., ADAMS, G., KLEIN, J., PEARSON, J., WATSON, K., PLATT, M.: Neuroethology of Primate Social Behavior. Proc. of the National Academy of Sciences, vol. 110, Supplement 2, 10387-10394. Jefferson Science Fellowships, April 3, 2013.

[20] BAREFOOT, J. C., GRONBAEK, M., JENSEN, G., SCHNOHR P., PRESCOTT, E.: Social Network Diversity and Risks of Ischemic Heart Disease and Total Mortality: Findings from the Copenhagen City Heart Study. American J. of Epidemiology, vol. 161, No. 10, 960-967, 2005. ISSN 0002-9262. 